Türkiye Tarımsal Araştırmalar Dergisi
dergipark.org.tr/tutad $\begin{aligned} & \text { Turk J Agric Res } \\ & \text { 2019, 6(2): 186-192 } \\ & \text { ○ TüTAD } \\ & \text { ISSN: 2148-2306 } \\ & \text { e-ISSN: 2528-858X } \\ & \text { doi: 10.19159/tutad.523682 }\end{aligned}$

\title{
Yerel Soğan (Allium cepa L.) Genotiplerinin Haploidiye Yatkınlığının Belirlenmesi"
}

\author{
Sinan ŞAHINALP, Faika YARALI KARAKAN"** \\ Kilis 7 Aralk Üniversitesi, Ziraat Fakültesi, Bahçe Bitkileri Bölümü, Kilis, TÜRKIYE
}

\begin{tabular}{|c|c|}
\hline Geliş Tarihi/Received: 07.02.2019 & Kabul Tarihi/Accepted: 27.06 .2019 \\
\hline ORCID ID (Yazar sirasina göre / by author order) & \\
\hline (1D) orcid.org/0000-0001-8908-8835 (1) orcid.org/0000-0002-2176-8663 & \\
\hline
\end{tabular}

Öz: Bu çalışmada, Türkiye'de yerel olarak yetiştirilen bazı soğan (Allium cepa L.) genotiplerinin çiçek tomurcuğu kültürü yoluyla haploidiye yatkınlıklarının belirlenmesi amaçlanmıştır. Araştırmada kallus oluşumu, kallusların bitkiye dönüşümü ve eksplantlardan doğrudan bitki gelişimi üzerine genotip etkisi önemli bulunmuştur. Çalışmada kalluslardan ve doğrudan bitki gelişimi yoluyla 39 adet bitki elde edilmiştir. Yapılan ploidi analizleri sonucu Şanlıurfa ili Siverek ilçesinden temin edilen 13 numaralı genotipten elde edilen bir adet bitkinin haploid olduğu tespit edilmiştir. Dolayısıyla, diğer genotiplerle karşılaştırıldığında, hem eksplantlarda kallus oluşumu hem de doğrudan bitki meydana getirme kabiliyetinin yüksek olduğu tespit edilen 12, 13 ve 5 numaralı genotiplerin, soğan ıslah programlarında haploid bitki elde etmede daha başarılı sonuçlar verebileceği düşünülmektedir.

Anahtar Kelimeler: Soğan, haploidi, gynogenezis, tomurcuk kültürü

\section{Determination of Haploidy Frequencies of the Locally Grown Onion (Allium cepa L.) Genotypes}

Abstract: In this study, it was aimed to determine the haploidy frequencies of the some locally grown onion (Allium cepa L.) genotypes in Turkey by flower bud culture. The effect of genotype on callus formation, callus transformation to plants and direct plant formation was found to be statistically significant. In the experiment, 39 plants were obtained from calluses and direct plant growth from flower buds. Ploidy analysis revealed that one of these plants, genotype number 13 obtained from (Siverek/Şanliurfa province), was haploid. Compared to others, genotypes 12, 13 and 5 were found to have high ability on both callus formation and direct plant formation. Therefore, it is thought that these genotypes can give more successful results in haploid plant production in onion breeding studies.

Keywords: Onion, haploidy, gynogenesis, flower bud culture

\section{Giriş}

Amaryllidaceae familyasina mensup olan soğan (Allium cepa L.) Türkiye'de olduğu gibi dünyada da yaygın olarak yetiştirilen bir sebze türüdür. Toplam 1.094.343.707 ton olan dünya sebze üretiminin 102.997.290 ton ile \% 9'unu soğan oluşturmaktadır (Anonymous, 2018). Türkiye'nin toplam sebze üretimi 30.825.569 ton olup; bu üretimin 138.993 tonunu taze soğan üretimi, 2.131.513 tonunu kuru soğan üretimi oluşturmaktadır. Türkiye'de soğan üretiminin toplam sebze üretimi içindeki payı ise \% 6.91'dir (Anonim, 2018).

Soğanda, tohumdan tohum üretimi 2-3 y1l sürmektedir. Bu nedenle soğanda 2-3 yılda bir generasyon ilerlenebilmekte, kendileme depresyonundan dolayı kendileme işlemine ancak 2

\footnotetext{
": Bu çalışma; Kilis 7 Aralık Üniversitesi, Fen Bilimleri Enstitüsü tarafından kabul edilen birinci yazara ait "Yerel Soğan (Allium cepa L.) Genotiplerinin Haploidiye Yatkınlığının Belirlenmesi” isimli Yüksek Lisans Tez çalışmasından üretilmiştir.
} 
veya 3 generasyon devam edilebilmektedir. $\mathrm{Bu}$ durum hibrit ıslahında ihtiyaç duyulan genotipik ve fenotipik homojenite gösteren ebeveyn saf hatların elde edilmesini güçleştirmektedir. Bu nedenle, 1slah çalışmalarında 1slah süresini kısaltmak, çeşit adaylarını ve özellikle hibrit çeşit ıslahında ebeveyn olarak kullanılan saf hatları kısa sürede geliştirmek önem kazanmaktadır. Biyoteknolojik yöntemlerden haploidi tekniği, ıslah çalışmalarının süresinin kısaltılmasında ve ebeveyn saf hatlarının kisa sürede elde edilmesinde büyük yarar sağlamaktadır (Bohanec, 2002; Alan ve ark., 2014; Dhatt ve Thakur, 2014; Yaral1, 2014; Khar ve ark., 2018; Singh ve ark., 2018).

Somatik hücrelerindeki kromozom say1s1, gamet hücrelerinde bulunan kromozom sayısı kadar olan bitkilere haploid bitki adı verilmektedir. Haploid bitkiler, her bir lokustaki allelerden sadece bir seriyi içermekte ve bu özellikleri ile 1slah çalışmalarında önemli kullanım alanı bulmaktadır. Haploid bitkilerin kromozom sayılarının katlanması ile tüm genomu homozigot saf hatlar elde edilebilmektedir. Böylece uzun yıllara gereksinim duyan saflaştırma işlemi, kısa sürede yapılabilmekte; kombinasyon 1slahı ve hibrit çeşit 1slahı programlarında zaman kazanılmaktadır (Chen ve ark., 2011; Dhatt ve Thakur, 2014; Yarall, 2014; Khar ve ark., 2018).

Haploid bitkiler, normal bitkilerde bulunan tüm organlara sahiptir ancak, diploidleri ile kıyaslandığında hücre, yaprak ve çiçekleri daha küçüktür ve bitki daha kısadır (Keller, 1990a; Sulistyaningsih ve ark., 1997). Haploid bitkilerin bitki ıslah programlarında kullanılabilmeleri için yeniden verimli diploid bitkilere dönüştürülmesi gerekmektedir. Haploid bir bitkinin kromozomlarının bazı kimyasal maddeler yardımiyla veya spontan olarak katlanması sonucunda kromozom sayısı diploid hale getirilmektedir. $\mathrm{Bu}$ işleme dihaploidleştirme (dihaploidizasyon), elde edilen bitkilere ise "katlanmış haploid" adi verilmektedir. Dihaploidizasyon tekniği kullanılarak hıyar, kabak, ayçiçeği, arpa, buğday, soğan, pırasa ve şekerpancarında katlanmış haploidlerin elde edildiği bildirilmektedir (Palmer ve Keller, 2005; Forster ve ark., 2007; Murovec ve Bohanec, 2012; Dhatt ve Thakur, 2014).

In vitro haploid embriyo ve bitki elde etmede kullanılan yöntemleri temel olarak androgenik ve gynogenik yöntemler olmak üzere iki grup altında toplamak mümkündür. $\mathrm{Bu}$ yöntemlerden ilkinde başlangıç materyali olarak erkek gamet (anter ve mikrospor kültürü), ikinci yöntemde ise dişi gamet (yumurta (ovul), yumurtalık (ovaryum) ve çiçek tomurcuğu) kullanılmaktadır. Ancak, her bitki türünde katlanmış haploidleri elde etmek mümkün olmamaktadır. Ayrıca, her tür, farklı dihaploidizasyon tekniğine tepki vermektedir. Yapılan çalışmalar sonucunda Allium türlerinin androgenezise tepki vermedikleri buna karşın gynogenezis yoluyla haploid bitkiler meydana getirebildikleri belirlenmiştir (Keller ve Korzun, 1996; Forster ve ark., 2007; Yaralı ve Yanmaz, 2013; Dhatt ve Thakur, 2014; Yaral1, 2014).

Gynogenezis çalışmalarında başarıyı etkileyen ana unsur kullanılan genotipin haploidiye yatkınlığıdır. Soğanda yapılan gynogenezis çalışmalarında, haploid embriyo oluşumu, embriyo oran1, rejenerasyon oran1, canlılık oran1, embriyo kalitesi ve ploidi seviyelerinin kullanılan genotipe bağlı olarak değiştiği bildirilmiştir (Jakse ve Bohanec 1994; Campion ve ark., 1995; Jakse ve ark., 1996; Geoffriau ve ark., 1997; Mukhambetzhanov, 1997; Bohanec ve Jakse, 1999; Michalik ve ark., 2003; Alan ve ark., 2004; Judkevieiene ve ark., 2005; Sulistyaningsih ve ark., 2006; Souri ve ark., 2007; Forodi ve ark., 2009).

Soğan ıslah çalışmalarında yurt dışında yaygın olarak kullanılan gynogenezis tekniğine ait uygulamalara Türkiye'de de son yıllarda başlanmıştır. Tekniğin kendi laboratuvar koşullarımıza optimizasyonunun sağlanabilmesi için denemeler yürütülmüş ve Türkiye'de soğan 1slahında çalışacaklara yol gösterici olacak sonuçlar elde edilmiştir (Alan ve ark., 2014; Yaralı 2014; Alan ve ark., 2017). Ancak, yerel çeşitlerin veya genotiplerin çoğunluğunun haploidiye tepkileri bilinmemektedir. Bu nedenle 1slah çalışmalarında Türkiye'nin soğan genotiplerinin gynogenezise yatkınlığının belirlenmesi ve gynogenezis meydana getirme kapasitesi yüksek çeşit veya genotiplerin soğan 1slah programlarına dâhil edilmesi önem arz etmektedir.

$\mathrm{Bu}$ çalışmada, Kilis ili ve çevresi başta olmak üzere Türkiye'nin farklı illerinde yerel olarak yetiştirilen soğan genotiplerinin haploidiye yatkınlığının belirlenmesi ve ümitvar görülen genotiplerin soğan ıslah programlarında kullanılma olanağının araştırılması hedeflenmiştir.

\section{Materyal ve Yöntem}

\subsection{Bitkisel materyal}

Araştırma, 2016-2018 yılları arasında, Kilis 7 Aralık Üniversitesi Ziraat Fakültesi Bahçe Bitkileri Bölümü, Tarımsal Araştırma ve Uygulama Merkezi ile İleri Teknoloji Uygulama ve Araştırma Merkezi'ne ait Bitki Doku Kültürü Laboratuvarı'nda yürütülmüştür. Araştırmada 13 adet soğan genotipi kullanılmıştır (Tablo 1). Soğan genotiplerine ait tohumluk başlar, 22.11.2016 
tarihinde Kilis 7 Aralık Üniversitesi, Tarımsal Araştırma ve Uygulama Merkezi'nde hazırlanan 20 litrelik saksılara dikilmiş ve kültürde kullanılacak çiçek tomurcukları elde edilmiştir.

Tablo 1. Araştırmada kullanılan soğan genotipleri ve temin edildikleri yerler

\begin{tabular}{cc}
\hline Genotip no & Temin edildiği yer \\
\hline G1 & Ceyhan/Adana \\
G2 & Merkez/Amasya \\
G3 & Bismil/Diyarbakır \\
G4 & Kirıhan/Hatay \\
G5 & Islahiye/ Gaziantep \\
G6 & Merkez/Kilis 1 \\
G7 & Merkez/Kilis 2 \\
G8 & Merkez/Kilis 3 \\
G9 & Merkez/Kilis 4 \\
G10 & Musabeyli/ Kilis 5 \\
G11 & Nizip/ Gaziantep \\
G12 & Merkez/Şanlıurfa 1 \\
G13 & Siverek/Şanlıurfa 2 \\
\hline
\end{tabular}

\subsection{In vitro kültür}

Kültürde kullanılacak olan çiçek tomurcukları antezisten 3-5 gün önce, çiçek tomurcukları açmadan ana bitkilerden alınarak \% 70'lik etil alkol içinde 3 dakika bekletildikten sonra, \% 15'lik clorox çözeltisi (\% 0.9 sodyum hipoklorit $+\% 0.1$ tween-20) içerisinde 30 dakika tutulmuş, ardından 3 defa distile su ile yıkanarak sterilizasyon işlemi tamamlanmıştır (Muren, 1989; Alan ve ark., 2003; Judkevieiene ve ark., 2005; Yaral1, 2014). Ön kültür ortamı olarak soğanda in vitro'da gynogenik embriyo uyartımı üzerine başarılı sonuçlar veren BDS (Dunstan ve Short, 1997) ortamı kullanılmıştır (Yaralı ve Yanmaz, 2013; Yaral1, 2014). Kültür ortamına bitki büyümesini düzenleyici madde olarak daha önceki araştırıcıların bulguları dikkate alınarak $2 \quad \mathrm{mg} \quad \mathrm{L}^{-1} \quad 2,4-\mathrm{D} \quad(2,4-$ Dichlorophenoxyacetic acid) ve $2 \mathrm{mg} \mathrm{L}^{-1}$ 6-BA (Benzylaminopurine), \% 0.7 oranında agar ilave edilerek pH'sı 5.8'e ayarlanmış ve $121{ }^{\circ} \mathrm{C}$ 'de 25 dakika süre ile otoklavda sterilizayon işlemi yapılmıştır (Jakse ve ark., 1996; Sulistyaningsih ve ark., 2006; Yaralı, 2014). Tomurcuklar, steril kabinde $15 \mathrm{ml}$ besin ortamı ile doldurulan steril petrilere, her petriye 15 adet olmak üzere yerleştirilmiştir. Her genotipten 15 petri hava almayacak şekilde streç film ile sarıldıktan sonra, $25{ }^{\circ} \mathrm{C}$ 'de, 16/8 saat gün uzunluğuna sahip bitki büyütme kabininde kültüre alınmıştır (Sulistyaningih ve ark., 2002, 2006; Yaral1, 2014). Ön kültür ortamında gelişen eksplantlar ve bitkicikler $30 \mathrm{ml}$ büyüme ortamı (EM) içeren cam kavanozlara transfer edilmiştir (Alan ve ark., 2003; Jakse ve ark., 2003; Yaralı, 2014) (Şekil 1 ve 2).

Denemede elde edilen bitkiciklerin gelişimi izlenmiş ve üç-dört yapraklı aşamaya gelen bitkilerin ploidi seviyeleri Pamukkale Üniversitesi Bitki Genetiği ve Tarımsal Biyoteknoloji Uygulama ve Araştırma Merkezi'ne ait laboratuvarda flow sitometri (Beckman Coulter Cell Lab Quanta SC Flow cytometer) yardımıyla belirlenmiştir (Alan ve ark., 2003).



Şekil 1. Kültür ortamındaki farklı gelişme aşamalarındaki eksplantlar: a) Kültür ortamına yeni alınmış tomurcuklar, b) Kültür ortamında tomurcukların açılması, c) Kültür ortamında tomurcukların şişmesi ve kallus oluşumu, d) Yumurtalığın içinden doğrudan sürgün gelişimi, e) Kök ve sürgün gelişimi 


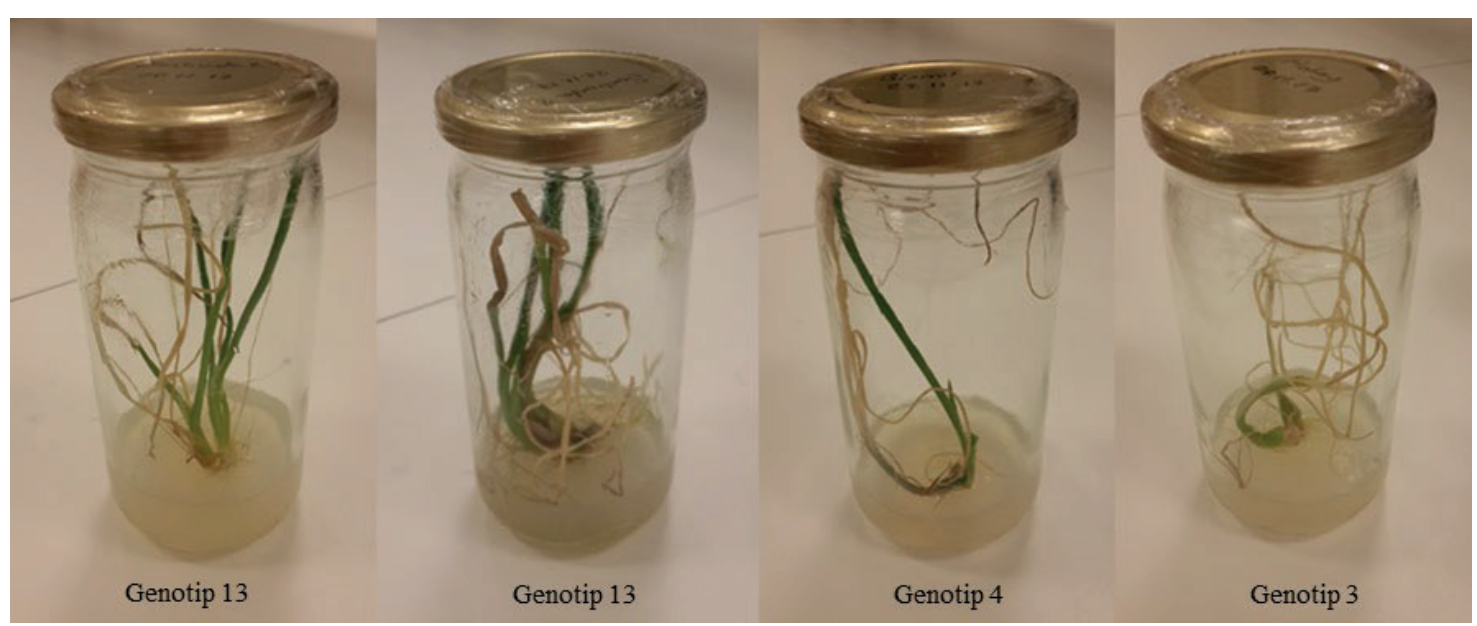

Şekil 2. Büyüme ortamında (EM) gelişmesini sürdüren bitkiler

\section{3. İstatistiki analiz}

Deneme, eksplantarda kallus oluşumu, kallusların bitkiye dönüşümü, doğrudan gelişen bitki sayısı ve haploid bitki oluşumu üzerine genotip etkisini belirlemek amaciyla tesadüf parselleri deneme düzenine göre kurulmuştur. Varyans analizlerini takiben farklı grupları belirlemek için Tukey testi kullanılmıştır. Hesaplamalar JMP paket programı ile yapılmıştır.

\section{Bulgular ve Tartışma}

\subsection{Eksplant gelişimi üzerine genotipin etkisi}

Varyans analizi sonuçlarına göre eksplantlarda kallus oluşumu üzerine genotip etkisi önemli bulunmuştur. En yüksek kallus oluşum oranının (\% 28.0) 11 numaralı genotipten elde edildiği, bunu sirasıyla ile $13(\% 27.13)$ ve 5 (\% 26.67) numaralı genotiplerin izlediği görülmektedir. En düşük kallus oluşum oranı ise $(\% 11.13) 1$ numaralı genotipten elde edilirken, 8 numaralı genotipte kallus oluşumu gözlenmemiştir (Tablo 2). Benzer şekilde, Keller (1990b) ile Hassandokht ve ark. (2000) yaptıkları çalışmalarda kallus oluşum oranlarının kullanılan tür ve çeşide göre farklılık gösterdiğini bildirmişlerdir.

Kallusların bitkiye dönüşümü bakımından da genotipler arasında farklılık olduğu, 3 numaralı genotipte 1 adet ve 11 numaralı genotipte ise 2 adet bitkinin kallustan meydana geldiği tespit edilmiştir (Tablo 2 ve Şekil 3). Ön kültür ortamındaki eksplantlardan doğrudan sürgün gelişimi yoluyla da in vitro bitkiler elde edilmiştir. Doğrudan sürgün gelişimi yoluyla bitki oluşumunda genotip etkisi önemli olmuş, kullanılan 13 genotipten 8'inde doğrudan sürgün gelişimi gözlenmiştir. Direkt sürgün gelişimi yoluyla elde edilen 36 bitkinin; $\%$ 4.87'si 5 numaralı genotipten, \% 4.47'si 13 numaralı genotipten, \% 3.13 'ü 12 numaralı genotipten, \% 1.80 'i 6 numaralı genotipten,

Tablo 2. Ön kültür ortamındaki eksplantların gelişimi üzerine genotipin etkisi (adet petri $\left.{ }^{-1}\right)^{1}$

\begin{tabular}{|c|c|c|c|c|c|c|c|c|}
\hline Genotip & $\begin{array}{l}\text { Kallus } \\
\text { oluşturan } \\
\text { eksplant } \\
\text { say1s.* }^{*}\end{array}$ & $\begin{array}{l}\text { Kallus } \\
\text { oluşturma } \\
\text { oranı } \\
(\%)\end{array}$ & $\begin{array}{l}\text { Kallustan } \\
\text { oluşan } \\
\text { bitki } \\
\text { sayısi* }^{* *}\end{array}$ & $\begin{array}{l}\text { Kallustan } \\
\text { oluşan } \\
\text { bitki oranı } \\
(\%)\end{array}$ & $\begin{array}{l}\text { Doğrudan } \\
\text { gelişen } \\
\text { bitki } \\
\text { sayısi }^{*}\end{array}$ & $\begin{array}{l}\text { Doğrudan } \\
\text { gelişen } \\
\text { bitki oranı } \\
(\%)\end{array}$ & $\begin{array}{c}\text { Camsılaşan } \\
\text { eksplant } \\
\text { sayısı }^{*}\end{array}$ & $\begin{array}{c}\text { Camsılaşan } \\
\text { eksplant } \\
\text { oranı } \\
(\%)\end{array}$ \\
\hline G1 & $1.67 \mathrm{~d}$ & 11.13 & $0.00 \mathrm{a}$ & 0.00 & $0.00 \mathrm{~b}$ & 0.00 & $1.33 \mathrm{gh}$ & 8.87 \\
\hline G2 & $2.67 \mathrm{~b}-\mathrm{d}$ & 17.80 & $0.00 \mathrm{a}$ & 0.00 & $0.00 \mathrm{~b}$ & 0.00 & $1.80 \mathrm{f}-\mathrm{h}$ & 12.00 \\
\hline G3 & $2.07 \mathrm{~cd}$ & 13.80 & $0.07 \mathrm{a}$ & 0.47 & $0.07 \mathrm{~b}$ & 0.47 & $3.53 \mathrm{c}-\mathrm{f}$ & 23.53 \\
\hline G4 & $2.87 \mathrm{a}-\mathrm{d}$ & 19.13 & $0.00 \mathrm{a}$ & 0.00 & $0.07 \mathrm{~b}$ & 0.47 & $5.20 \mathrm{~cd}$ & 34.67 \\
\hline G5 & $4.00 \mathrm{ab}$ & 26.67 & $0.00 \mathrm{a}$ & 0.00 & $0.73 \mathrm{a}$ & 4.87 & $3.13 \mathrm{~d}-\mathrm{g}$ & 20.87 \\
\hline G6 & $3.33 \mathrm{a}-\mathrm{c}$ & 22.20 & $0.00 \mathrm{a}$ & 0.00 & $0.27 \mathrm{ab}$ & 1.80 & $3.80 \mathrm{c}-\mathrm{f}$ & 25.33 \\
\hline G7 & $2.73 \mathrm{a}-\mathrm{d}$ & 18.20 & $0.00 \mathrm{a}$ & 0.00 & $0.00 \mathrm{~b}$ & 0.00 & $8.07 \mathrm{a}$ & 53.80 \\
\hline G8 & $0.00 \mathrm{e}$ & 00.00 & $0.00 \mathrm{a}$ & 0.00 & $0.00 \mathrm{~b}$ & 0.00 & $0.00 \mathrm{~h}$ & 0.00 \\
\hline G9 & $1.80 \mathrm{~d}$ & 12.00 & $0.00 \mathrm{a}$ & 0.00 & $0.00 \mathrm{~b}$ & 0.00 & $5.53 \mathrm{bc}$ & 36.87 \\
\hline G10 & $3.33 \mathrm{a}-\mathrm{c}$ & 22.20 & $0.00 \mathrm{a}$ & 0.00 & $0.07 \mathrm{~b}$ & 0.47 & $7.33 \mathrm{ab}$ & 48.87 \\
\hline G11 & $4.20 \mathrm{a}$ & 28.00 & $0.13 \mathrm{a}$ & 0.87 & $0.07 \mathrm{~b}$ & 0.47 & $4.47 \mathrm{~cd}$ & 29.80 \\
\hline G12 & $3.93 \mathrm{ab}$ & 26.20 & $0.00 \mathrm{a}$ & 0.00 & $0.47 \mathrm{ab}$ & 3.13 & $3.93 \mathrm{c}-\mathrm{e}$ & 26.20 \\
\hline G13 & $4.07 \mathrm{ab}$ & 27.13 & $0.00 \mathrm{a}$ & 0.00 & $0.67 \mathrm{a}$ & 4.47 & $1.93 \mathrm{e}-\mathrm{h}$ & 12.87 \\
\hline
\end{tabular}

1: Aynı sütunda farklı harfle gösterilen ortalamalar arasındaki farklılık istatistiki açıdan önemlidir, *: $\mathrm{p} \leq 0.05$ düzeyinde önemli farklılık, **: $\mathrm{p} \leq 0.01$ düzeyinde önemli farkl1l1k 


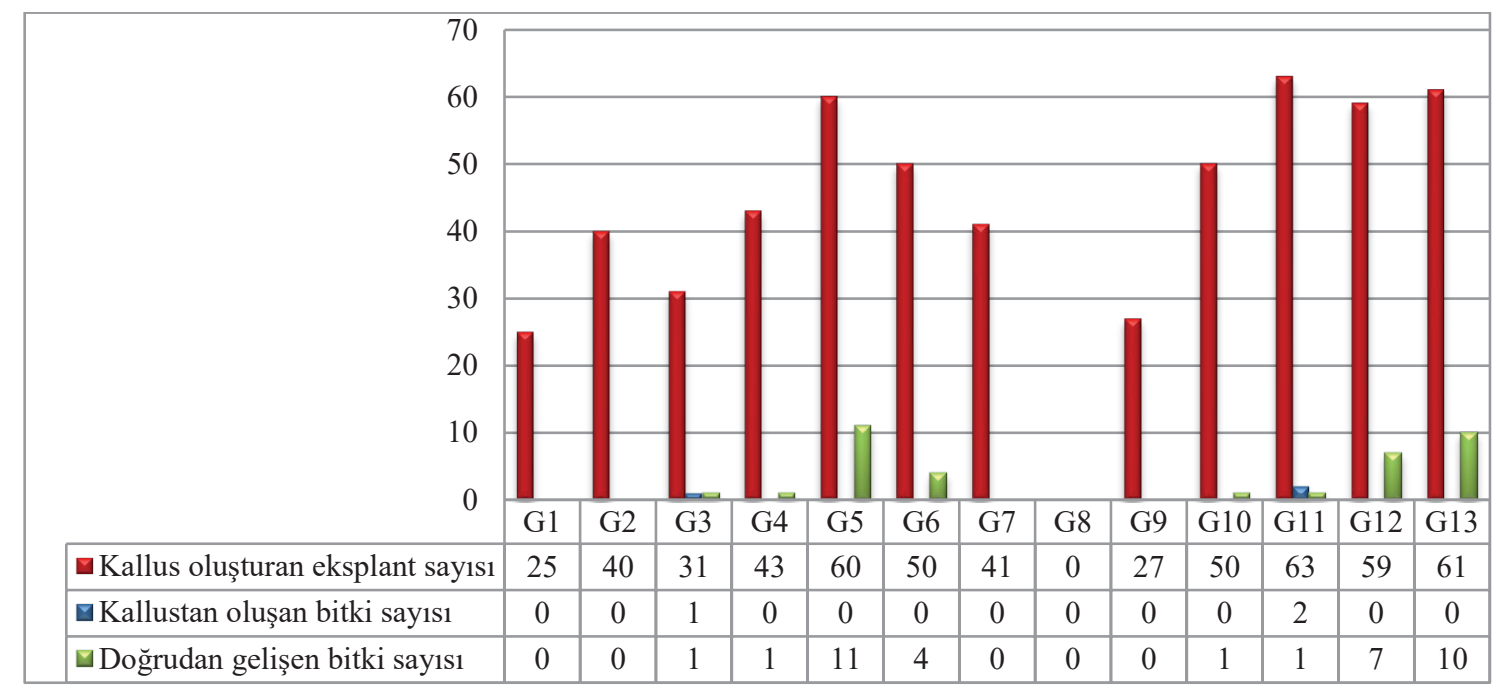

Şekil 3. Farklı soğan genotiplerinde kallus oluşturan eksplant sayıları ile kallustan ve doğrudan gelişen bitki sayıları

$\% 0.47$ 'si ise $3,4,10$ ve 11 numaralı genotiplerden elde edilmiş; 1, 2, 7, 8 ve 9 numaralı genotiplerde doğrudan bitki gelişimi gözlenmemiştir (Tablo 2 ve Şekil 3). Keller (1990a) tarafindan yürütülen ve soğanda ilk haploid bitkinin elde edildiği çalışmada, farklı Allium türleri ve farklı soğan çeşitleri kullanılmış ve sadece soğanda yumurta hücresinden bitki rejenerasyonunun meydana geldiği, kültüre alınan yumurtalıklardan genotiplere göre \% 0.08 0.58 arasında değişen oranlarda doğrudan embriyo gelişimi ile bitkicikler elde edildiği bildirilmiştir. Genetik orijinlerine (Kuzey Avrupa, Doğu Avrupa, Güney Avrupa, Amerika Birleşik Devletleri) ve genetik yapılarına göre (açık tozlanan, kendilenmiş, sentetik klon) ayrılan 22 soğan çeşidinin kullanıldığı başka bir araştırmada ise; gynogenik embriyo oluşumu üzerine genotip ve çeşit etkisinin önemli olduğu, kültüre alınan çiçek tomurcuklarında embriyo verimi ve bitki rejenerasyonunun \% 0-17 ve \% $0-11$ arasında değiştiği bildirilmiştir (Geoffriau ve ark., 1997). Benzer şekilde Bohanec ve Jakse (1999), Avrupa, Kuzey Amerika ve Japonya orijinli uzun gün soğan çeşitleri ile yaptıkları çalışmada; ana bitkiler arasında gynogenik embriyo veriminin dikkate değer ölçüde farkl1lık gösterdiği, ortalama embriyo veriminin \% 18.6-22.6 arasında değiștiği ve Amerika orijinli 1slah materyalinin, Avrupa ve Japonya orijinli olanlara göre ortalama olarak 5 ve 9 kat daha fazla gynogenik embriyo meydana getirme kabiliyetine sahip olduğu ortaya çıkarılmıştır. Bohanec ve ark. (2001) tarafindan yapılan 39 farklı uzun gün soğan genotipinin kullanıldığı araştırmada da benzer sonuçlara ulaşılmış, soğanda haploidi meydana gelme frekansının büyük oranda genotipe bağlı olduğu belirlenmiştir. Benzer şekilde, İspanyol soğan çeşitlerinin gynogenezise yatkınlığının ve embriyo meydana getirme kabiliyetlerinin birbirinden farklı olduğu tespit edilmiştir (Fayos ve ark., 2015).

Kalluslardan ve doğrudan sürgün gelişimi yoluyla meydana gelen toplam 39 bitkicik büyüme ortamına (EM) transfer edilmiştir. Bu ortamda 13 numaralı genotipe ait sadece 2 bitki yaşatılabilmiştir. Flow sitometri kullanılarak 3-4 yaprağa sahip bitkilerden alınan örneklerde ploidi seviyesi belirlenmiş, elde edilen bitkilerden birinin haploid, diğerinin ise diploid olduğu belirlenmiştir (Tablo 3).

Tablo 3. In vitro'da elde edilen bitkilerde yapılan ploidi analizi sonuçları

\begin{tabular}{lcc}
\hline Analiz edilen materyal & $\begin{array}{c}\text { Nükleer DNA } \\
\text { miktarı }\end{array}$ & $\begin{array}{c}\text { Ploidi } \\
\text { seviyesi }\end{array}$ \\
\hline Diploid soğan (kontrol) & 33.49 & $2 \mathrm{n}$ \\
Genotip 13 (Şanlıurfa 2) & 31.03 & $2 \mathrm{n}$ \\
Genotip 13 (Şanlıurfa 2) & 16.79 & $\mathrm{n}$ \\
\hline
\end{tabular}

Araştırma sırasında eksplantlarda camsılaşma ve gelişmeyen tomurcuklardan dolayı kayıplar yaşanmıştır. Ön kültür ortamında kültüre alınan tomurcuklarda meydana gelen kayıplar da genotipler arasında farklılık göstermiştir (Tablo 2 ve Şekil 4). En yüksek camsılaşma oranına (\% 53.80) 7 numaralı genotipin sahip olduğu, bunu sirasıly \% 48.87 oran ile 10 numaral genotipin ve \% 36.87 ile 9 numaralı genotipin izlediği; en düşük camsılaşma oranına (\% 8.87) ise 1 numaralı genotipin sahip olduğu görülmektedir (Tablo 2). Besin ortamındaki yüksek karbonhidrat, oksin ve sitokinin miktarının camsılaşmaya neden olduğu farklı araştırıcılar tarafından bildirmiştir (Paques ve Boxus, 1987; Ziv, 1991). Yaralı (2014) tarafindan yapılan çalışmada da, ortam bileşimindeki oksin ve 
sitokinin dozunun artmasıyla camsılaşma oranının $\operatorname{arttığ1~tespit~edilmiştir.~Ön~kültür~ortamında~}$ gelişmeyen eksplantların genotiplere göre dağılımı Şekil 4'te verilmiştir. Şekil 4 incelendiğinde, en yüksek gelişmeyen eksplant sayısına (145) 8 numaralı genotipin, en az gelişmeyen eksplant sayısına (33) ise 10 numaralı genotipin sahip olduğu görülmektedir.

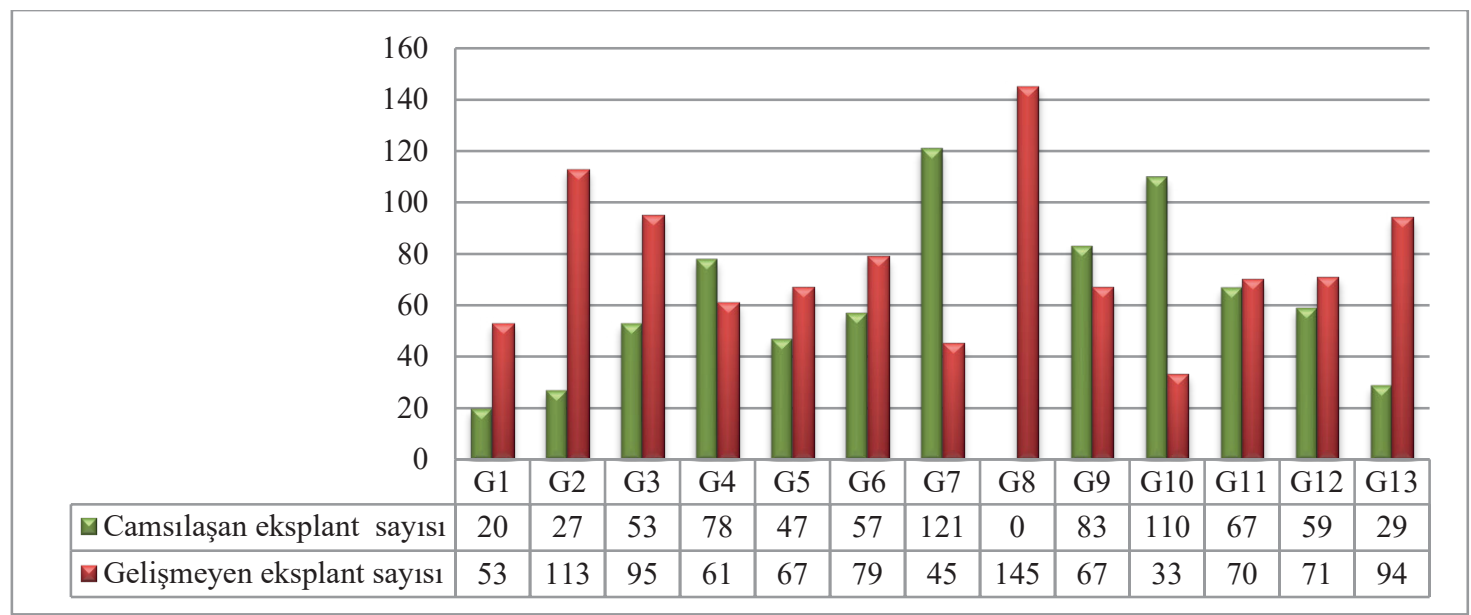

Şekil 4. Farklı soğan genotiplerinde camsılaşan ve gelişmeyen eksplant sayıları

\section{Sonuçlar}

Yapılan bu çalışmada, Türkiye'de yetiştirilen bazı yerel soğan genotiplerinin haploidiye yatkınlığının tespiti ve ümitvar görülen genotiplerin soğanda yapılacak ıslah çalışmalarında kullanılması için referans bitki adaylarının belirlenmesi hedeflenmiştir. Araştırmada kallus oluşumu, kallusların bitkiye dönüşümü ve eksplantlardan doğrudan bitki gelişimi üzerine genotip etkisi önemli bulunmuştur. Çalışmada kalluslardan ve doğrudan bitki gelişimi yoluyla 39 adet bitki elde edilmiştir. Yapılan ploidi analizleri sonucu Şanlıurfa ili Siverek ilçesinden temin edilen 13 numaralı genotipten elde edilen bir adet bitkinin haploid olduğu tespit edilmiştir. Dolayısıyla hem eksplantlarda kallus oluşumu hem de doğrudan bitki meydana getirme kabiliyetlerinin yüksek olduğu tespit edilen 12,13 ve 5 numaralı genotiplerin diğer genotiplerle kıyaslandığında, soğan 1slahı çalışmalarında haploid bitki elde edilmesi açısından daha başarılı sonuçlar verebileceği düşünülmektedir.

\section{Teşekkür}

Bu çalışma; Kilis 7 Aralık Üniversitesi Bilimsel Araştırmalar Birimi (BAP) tarafindan "10967" No'lu proje ile desteklenmiştir.

\section{Kaynaklar}

Alan, A.R., Mutschler, M.A., Brants, A., Cobb, E., Earle, E.D., 2003. Production of gynogenic plants from hybrids of Allium cepa L. and A. roylei stearn. Plant Science, 165(6): 1201-1211.

Alan, A.R., Brants, A., Cobb, E., Goldschmied, A., Mutschler, M.A., Earle, E.D., 2004. Fecund gynogenic lines from onion (Allium cepa L.) breeding materials. Plant Science, 167(5): 1055-1066.

Alan, A.R., Kaska, A., Celebi-Toprak, F., 2014. Production of fully homozygous genotypes from various edible Alliums. International Journal of Secondary Metabolite (Special Issue-Abstracts), 1(1): 77.

Alan, A.R., Kaska, A., Aslan, E., Celebi-Toprak, F., 2017. Turkish doubled haploid onion (A. cepa L.) lines. The 3rd International Symposium on EuroAsian Biodiversity, 05-08 July, Minsk, BELARUS, pp. 114.

Anonim, 2018. Bitkisel Üretim İstatistikleri. Türkiye İstatistik Kurumu (https://biruni.tuik.gov.tr/medas/? $\mathrm{kn}=92$ \&locale=tr), (Erişim tarihi: 24.12.2018).

Anonymous, 2018. FAO Statistics Division. (http:// faostat.fao.org/site/567/DesktopDefault.aspx?PageI $\mathrm{D}=567$ \#ancor), (Erişim tarihi: 24.12.2018).

Bohanec, B., Jakse, M., 1999. Variations in gynogenic response among long-day onion (Allium cepa L.) accessions. Plant Cell Reports, 18(9): 737-742.

Bohanec, B., Jakse, M., Javornik, B., 2001. Present status of haploid induction in onion: analysis of procedure and its limitations. Acta Horticulturae, 555: 91-98.

Bohanec, B., 2002. Doubled haploid onions. In: H. Rabinowich and L. Currah (Eds.), Allium Crop Science: Recent Advances, CABI Publishing House, Wallingford, UK, pp. 145-148.

Campion, B., Perri, E., Azzimonti, M.T., Vicini, E., Schiavi, M., 1995. Spontaneous and induced 
chromosome doubling in gynogenic lines of onion (Allium cepa L.). Plant Breeding, 114(3): 243-246.

Chen, J.F., Cui, L., Malik, A.A., Mbira, K.G., 2011. In vitro haploid and dihaploid production via unfertilized ovule culture. Plant Cell, Tissue and Organ Culture (PCTOC), 104(3): 311-319.

Dhatt, A., Thakur, S.P., 2014. Production of doubled haploids in onion: A review. Journal of Horticultural Sciences, 9(2): 107-112.

Dunstan, D.I., Short, K.C., 1997. Improved growth of tissue cultures of onion, Allium cepa. Physiol Plant, 41(1): 70-72.

Fayos, O., Vallés, M.P., Garcés-Claver, A., Mallor, C., Castillo, A.M., 2015. Doubled haploid production from Spanish onion (Allium cepa L.) germplasm: embryogenesis induction, plant regeneration and chromosome doubling. Frontiers in Plant Science, 6(384): 1-11.

Forodi, B.R., Hassandokht, M., Kashi, A., Sepahvand, N., 2009. Influence of spermidine on haploid plant production in Iranian onion (Allium cepa L.) populations through in vitro culture. Horticulture Environment and Biotechnology, 50(5): 461-466.

Forster, B.P., Bors, E.H., Kasha, K.J., Touraev, A., 2007. The Resurgence of haploids in higher plants. Trends in Plant Science, 12(8): 368-375.

Geoffriau, E., Kahane, R., Rancillac, M., 1997. Variation of gynogenesis ability in onion (Allium cepa L.). Euphytica, 94(1): 37-44.

Hassandokht, M.R., Kashi, A., Campion, B., Bozorgipour, R., 2000. Study of haploid production in Iranian onions (Allium cepa L.) via in vitro gynogenesis. Seed and Plant, 16(3): 300-312.

Jakse, M., Bohanec, B., 1994. Effect of media composition on gynogenesis of onion cultivars. In: B. Javornik and B. Bohanec, I. Kreft (Eds.), Proceedings of The International Colloquium on Impact of Plant Biotechnology on Agriculture, Ljubljana, pp. 35-41.

Jakse, M., Bohanec, B., Ihan, A., 1996. Effect of media components on the gynogenic regeneration of onion (Allium cepa L.) cultivars and analysis of regenerants. Plant Cell Reports, 15(2): 934-938.

Jakse, M., Havey, M.J., Bohanec, B., 2003. Chromosome doubling procedures of onion (Allium cepa L.) gynogenic embryos. Plant Cell Reports, 21(9): 905910.

Judkevieiene, D., Stanys, V., Bobinas, E., 2005. Gynogenesis pecularities of Allium L. vegetables grown in Lithuania. Bologija, 3: 6-9.

Keller, J., 1990a. Culture of unpollinated ovules, ovaries and flower buds in some species of the genus Allium and haploid induction via gynogenesis in onion (Allium cepa L.). Euphytica, 47(3): 241-247.

Keller, J., 1990b. Results of anther and ovule culture in some species and hybrids in the genus Allium L. Archiv für Züchtungsforschung, 20(3): 189-197.

Keller, E.R.J., Korzun, L., 1996. Haploidy in onion (Allium cepa L.) and other Allium species. in vitro haploid production in higher plants. In: S.M. Jain, S.K. Sopory and R.E. Villeuks (Eds.), Kluwer Academic Publisher, Netherlands, pp. 51-75.
Khar, A., Kumar, A., Islam, S., Kumar, A., Agarwal, A., 2018. Genotypic response towards haploid induction in short day tropical Indian onion (Allium cepa). Indian Journal of Agricultural Sciences, 88(5): 709713

Michalik, B., Adamusa, A., Nowak, E., 2003. Gynogenesis in Polish onion cultivars: gametic embryogenesis. Plant Science, 165(6): 1201-1211.

Mukhambetzhanov, S.K., 1997. Culture of nonfertilized female gametophytes in vitro. Plant Cell, Tissue and Organ Culture, 48(2): 111-119.

Muren, R., 1989. Haploid plant induction from unpollinated ovaries in onion. HortScience, 24(5): 833-834.

Murovec, J., Bohanec, B., 2012. Haploids and doubled haploids in plants breeding. In: I.Y. Abdurakhmonov (Ed.), Plant Breeding, Rijeka, pp. 87-106.

Palmer, C.E.D., Keller, W.A., 2005. Overview of haploidy. In: C.E. Palmer, W.A. Keller and K.H. Kasha (Eds.), Biotecnology in Agriculture and Forestry, Haploids in Crop Imprevement II, pp. 3-7.

Paques, M., Boxus P.H., 1987. "Vitrification": Review of literature. Acta Horticulturae, 212: 155-166.

Singh, D., Dhillon, T.S., Singh, R., Kumar, R., 2018. Present status and future opportunities in onion research: A review. International Journal of Chemical Studies, 6(1): 656-665.

Souri, N.A., Hassandokht, M.R., Peyvast, G.H.A., 2007. Effect of different sugars on in vitro haploid plants production of Iranian onion landraces (Allium cepa L.). Iranian Journal of Agricultural Science, 38(3): 459-465.

Sulistyaningsih, E., Tashiro, Y., Shigyo, M., Isshiki, S., 1997. Morphological and cytological characteristics of haploid shallot (Allium cepa L. Aggregatum group). Bulletin of the Faculty of Agriculture-Saga University (Japan), 82: 7-15.

Sulistyaningsih, E., Yamashita, K., Tashiro, Y., 2002. Haploid induction from F1 hybrids between CMS shallot with Allium galanthum cytoplasm and common onion by unpollinated flower culture. Euphytica, 125: 139-144.

Sulistyaningsih, E., Aoyagi, Y., Tashiro, Y., 2006. Flower bud culture of shallot (Allium cepa L. Aggregatum group) with cytogenetic analysis of resulting gynogenic plants and somaclones. Plant Cell Tissue and Organ Culture, 86: 249-255.

Yaralı, F., Yanmaz, R., 2013. Allium türlerinin 1slahında haploidi tekniğinden yararlanma. Türk Bilimsel Derlemeler Dergisi, 6(2): 44-50.

Yaralı, F., 2014. Soğan (Allium cepa L.) ve Tunceli sarımsağ1 (Allium tuncelianum Kollman, Özhatay, Matthew, Şiraneci)'nda ovaryum ve çiçek tomurcuğu kültürü yoluyla haploid bitki elde etme olanaklarının araştırılması. Doktora tezi, Ankara Üniversitesi Fen Bilimleri Enstitüsü, Ankara.

Ziv, M., 1991. Vitrification: morphological and physiogical disorders of in vitro plants. Micropropagation, 45-69. 